\title{
NUMERICAL SIMULATION OF SEAWALL- BEACH PROFILE INTERACTION IN RUNUP ZONE
}

\author{
Berna Ayat $^{1}$, Nobuhisa Kobayashi², Yalçın Yüksel ${ }^{1}$, and Burak Aydoğan ${ }^{1}$
}

\begin{abstract}
This study aimed to determine beach response in the presence of a vertical wall placed in the run-up zone. The responses of natural beach and the beach with a seawall with two different configurations were studied numerically. The capability and limitation of the cross-shore numerical model CSHORE in simulating the cross-shore transformation and the beach evolution in front of a seawall situated inside the surf zone was examined. Numerical model results were compared with small scale laboratory tests (Yüksel et. al, 2014). Offshore transport was observed in all three tests and the model was shown to predict the same trends in profile evolution. Scour depth in front of the vertical wall was correctly captured by the numerical model.
\end{abstract}

Keywords: seawall; CSHORE; beach profile; sediment transport; scour

\section{INTRODUCTION}

Seawalls are common coastal protection structures against storm surges, waves and coastal flooding. These structures are commonly placed on sandy seabed. High energy waves during storm action may cause toe scour. Toe scour may induce damage or collapse of the structures. Due to this important risk, toe scour of a seawall has been a major research concern for coastal engineers so far. But another important concern for the coastal engineering community is the effect of seawall on the beach profile evolution. Previous experiences showed that vertical seawalls could be controversial. They are built under the erosive conditions and they may accelerate the erosion due to the highly reflective characteristics. Effect of the seawall on the beach profile in front of it has been investigated heavily for the mild slope beaches previously. But studies considering steep slopes are rare. Barnett et. al., (1988) made the first attempt on this issue. Authors conducted an experimental study to determine beach profile response due to the presence of a vertical seawall placed in various cross-shore positions, and they examined the differences between natural beaches and seawall- backed beaches in response to normally incident wave attack.

Yüksel et. al. (2012) conducted an experimental study to examine the deposition process at the toe of the seawall in runup region in various locations over the 1/10 sloping beach. Authors concluded that the process depends on wave steepness, run-up height, and location of the wall. This study followed by another experimental study (Yüksel et. al., 2014) where the erosion and deposition processes in front of the vertical wall over a steeper slope were investigated.

This study aims to validate the cross-shore numerical model CSHORE for the examination of the seawall beach profile interaction problem based on the small scale coarse sand laboratory tests. CSHORE has been validated against different kinds of problems by using small (Saitoh and Kobayashi, 2012; Hicks et. al., 2010) and large scale laboratory data as well as field data. Johnson et al. (2012) presented a validation of the CSHORE against broad range of field data including 50 beach profile measurements from seven different sites and six different storm sequences. Model performance was evaluated based on the comparison of measured and calculated volume change, recession of select profile contours, and the landward progression of damaging erosion. They concluded that the model provided satisfactory estimates of storm induced beach erosion for various pre-storm beach profile shapes and conditions. They mentioned that further efforts are needed to improve the calculation of the sediment transport and morphology evolution in the intermittently wet zone.

In this study CSHORE was used to simulate the impact of the vertical seawall on the beach profiles. Experimental data collected by Yüksel et. al., 2014 were used to validate the numerical model. In the following, the experimental study by Yüksel et. al. (2014) was summarized first. Secondly, the hydrodynamics and the wave transformation along the wave flume were evaluated based on both the measured and computed data. Third, the cross-shore sediment transport and the beach profile evolution were examined comparatively. Finally, the summary of this study and the key findings were discussed.

\footnotetext{
${ }^{1}$ Department of Civil Engineering, Yildiz Technical University, Davutpaşa, Esenler, İstanbul, 34220, Turkiye

2 Center for Applied Coastal Research, Univ. of Delaware, Newark, DE 19716, USA.
} 


\section{EXPERIMENTAL STUDY}

The experiments were carried out in the Coastal and Harbor Engineering Laboratory in Yildiz Technical University by Yüksel et al. (2014). The two dimensional wave flume with a length of 26m, width of $1 \mathrm{~m}$, and a depth of $1 \mathrm{~m}$ was used (Figure 1). The flume is equipped with an irregular piston type wave generator. It consists of two interconnected shapes that rotate relative to each other. The wave maker measures the incoming wave and corrects the paddle motion to absorb it. Both sides of the steel flume were made of glass for observations. The beach was modelled using 1/6 sloping steel ramps and sand laying on a uniform beach slope. The thickness of the sand layer above the steel ramp was 22 $\mathrm{cm}$ initially at each test.

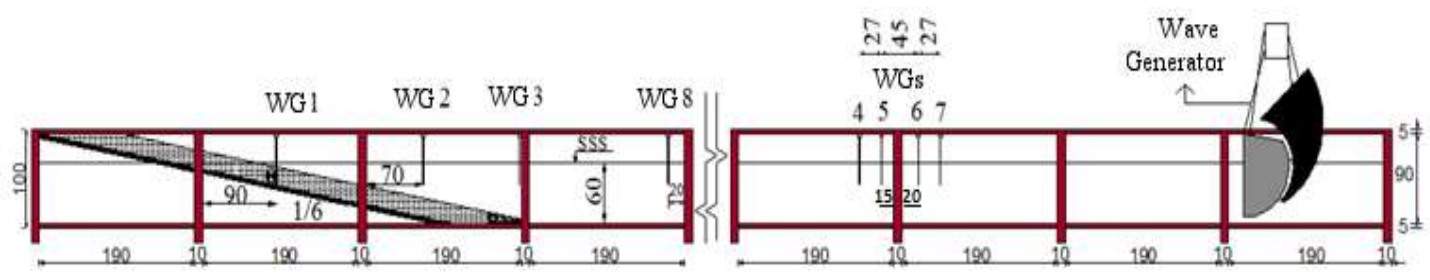

Figure 1. Experimental Setup and equipment.

Sand with diameter characteristics of $\mathrm{d}_{50}=1.28 \mathrm{~mm}, \mathrm{~d}_{90}=1.89 \mathrm{~mm}$, and $\sigma=1.57$ (where $\sigma$ is standard deviation) was used for bed conditions. Specific weight of the sand was $\gamma=26500 \mathrm{~N} / \mathrm{m}^{3}$.

The tests have been carried out under irregular wave conditions shown in Table 1. For irregular waves the incident wave spectrum used was the JONSWAP spectrum. The significant wave height was approximately $\mathrm{H}_{\mathrm{s}}=14 \mathrm{~cm}$ and the peak wave period was between $\mathrm{T}_{\mathrm{p}}=1.64-1.71 \mathrm{~s}$ (Table 1). The water depth in the flume was $0.60 \mathrm{~m}$ for all tests. Surface elevations above the SWL $(\eta)$ were recorded by using eight resistive-type wave gauges (WG) which were installed along the centerline of the flume. Four wave gauges (WG4-WG7) were located outside the surf zone over the impermeable horizontal bed. These wave gauges were used to separate the incident and reflected waves and to estimate the reflection coefficient. WG1-WG3 were used to record the wave transformation over the sloping sandy beach. The sand beach profiles were measured using HR Wallingford bed profiler along three lines. Three measured profiles were averaged and used to evaluate the results.

Test procedure can be summarized as follows: First the initial beach profile having 1/6 slope was created and measured. All the wave gauges were calibrated accordingly in order to make sure that the recorded surface elevations were correct. The irregular waves were generated and recorded till the quasi-equilibrium bed conditions were reached. The quasi-equilibrium state of the beach profile has been decided via visual observations. The quasi-equilibrium bed profile has been reached within the first three hours of each test. The bottom elevations could only be measured before and after the irregular wave action. The intermediate beach profile evolution has not been measured in these experiments. Irregular waves were measured for the first 15 minutes of each hour. This procedure has been repeated for three different test setups. First the original beach profile (Without Wall-WW) test without any seawall has been conducted to observe the natural beach response. Then the vertical, smooth and impermeable plexiglass seawall model has been situated at $20 \mathrm{~cm}$ behind the SWL inside the runup zone (W20 test). For the third test seawall model has been situated $40 \mathrm{~cm}$ behind the SWL (W40 test). The interaction between the bed profile and the vertical wall at different locations inside the run-up zone was studied.

\begin{tabular}{|l|l|l|l|l|}
\hline \multicolumn{5}{|c|}{ Table 1. Wave conditions during the tests. } \\
\hline & Run & WW & W20 & W40 \\
\hline \multirow{2}{*}{$\mathrm{H}_{\mathrm{m} 0}(\mathrm{~cm})$} & Start & 13.2 & 14.3 & 13.5 \\
& End & 12.3 & 14.0 & 13.5 \\
$\mathrm{~T}_{\mathrm{p}}(\mathrm{s})$ & Start & 1.71 & 1.67 & 1.64 \\
& End & 1.67 & 1.67 & 1.67 \\
\hline
\end{tabular}

\section{HYDRODYNAMICS and WAVE TRANSFORMATION}

Instantaneous free surface elevations recorded at eight wave gauges were analyzed by means of mean, $\bar{\eta}$ and standard deviations, $\sigma_{\eta}$ for all three tests. These statistical parameters from WG7 were 
used to define the offshore wave characteristics in the numerical model domain. The spectral significant wave height $\mathrm{H}_{\mathrm{m} 0}=4 \sigma_{\eta}$ and spectral peak wave period $\mathrm{T}_{\mathrm{p}}$ were also calculated and defined based on this statistics at WG7. Wave transformation including wave shoaling, and reflection were determined from the statistics of the remaining wave gauges on the slope. The measured statistics $\left(\bar{\eta}\right.$ and $\left.\sigma_{\eta}\right)$ for the first and the last runs of WW test were shown in Figure 2. The free surface statistics at the beginning and at the end of the tests showed small variability in the hydrodynamics. This proved that the test procedure was acceptable.

The cross-shore variations of the hydrodynamics and the wave transformation were also studied numerically by using the cross-shore numerical model CSHORE. Computed hydrodynamics and the wave transformation were shown in Figure 2 together with the measured statistics for WW test. The statistics of measured free surface elevations at WG7 were used as the seaward boundary conditions of the numerical model. The wave model in CSHORE is based on the time-averaged continuity, momentum, and energy equations.

Unfortunately, current velocities couldn't be measured during the experimental study. Only the predicted mean $\bar{U}$ and standard deviation $\sigma_{\mathrm{U}}$ of the cross-shore velocity for WW test were shown in Figure 2.

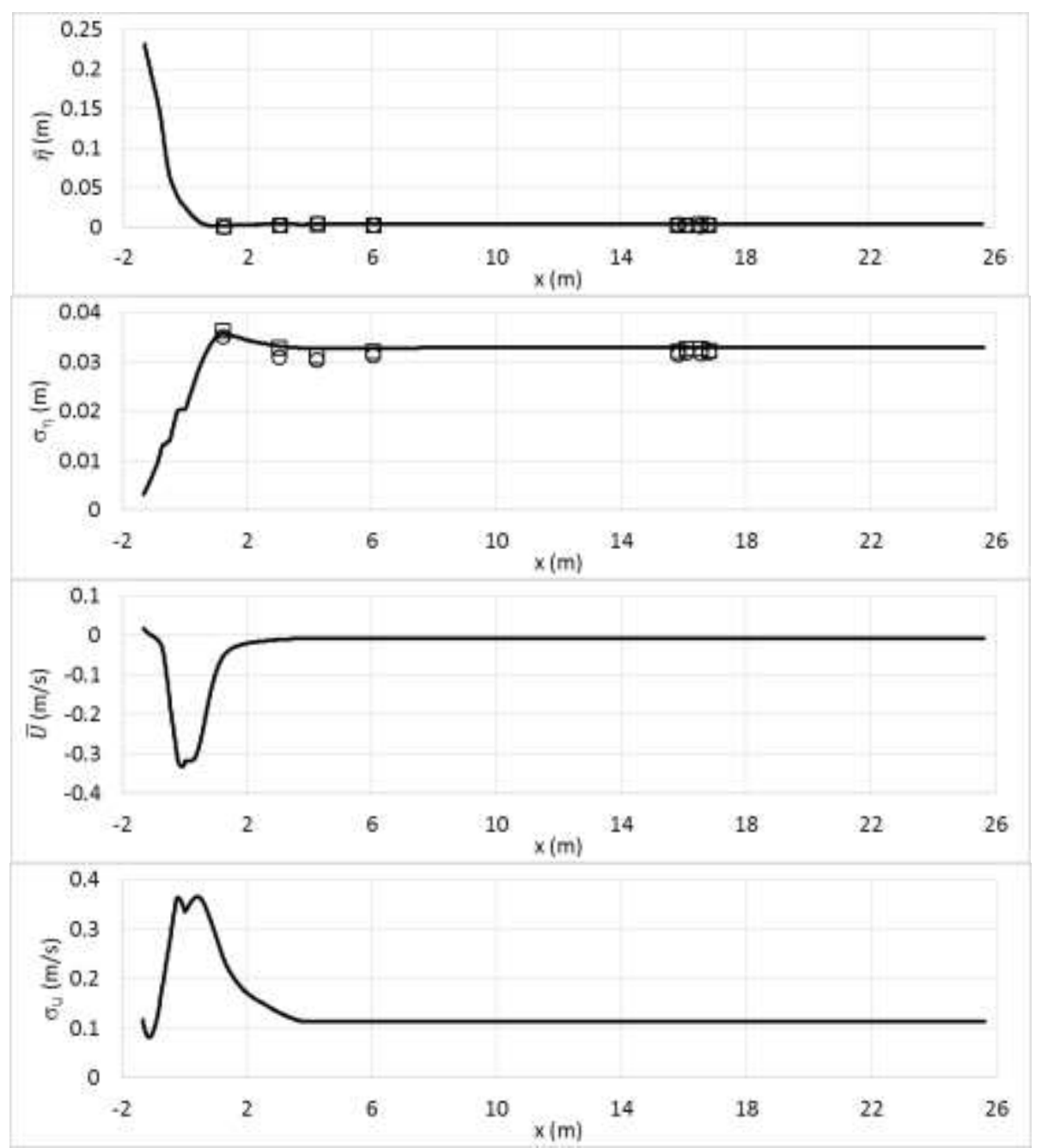

Figure 2. The comparison of measured and numerically predicted values of the hydrodynamic statistics for test WW. Top panel: the mean free surface elevation $\bar{\eta}$, second panel: the standard deviation of the free surface elevation $\sigma_{\eta}$, third panel: the mean cross-shore velocity $\bar{U}$, bottom panel: the standard deviation of the cross-shore velocity $\sigma_{\mathrm{U}}$. 
Similarly, the hydrodynamics and wave transformation data based on the statistics of the measured instantaneous free surface elevations and predicted by the numerical model are shown in Figure 3 for W20 test and in Figure 4 for W40 test.

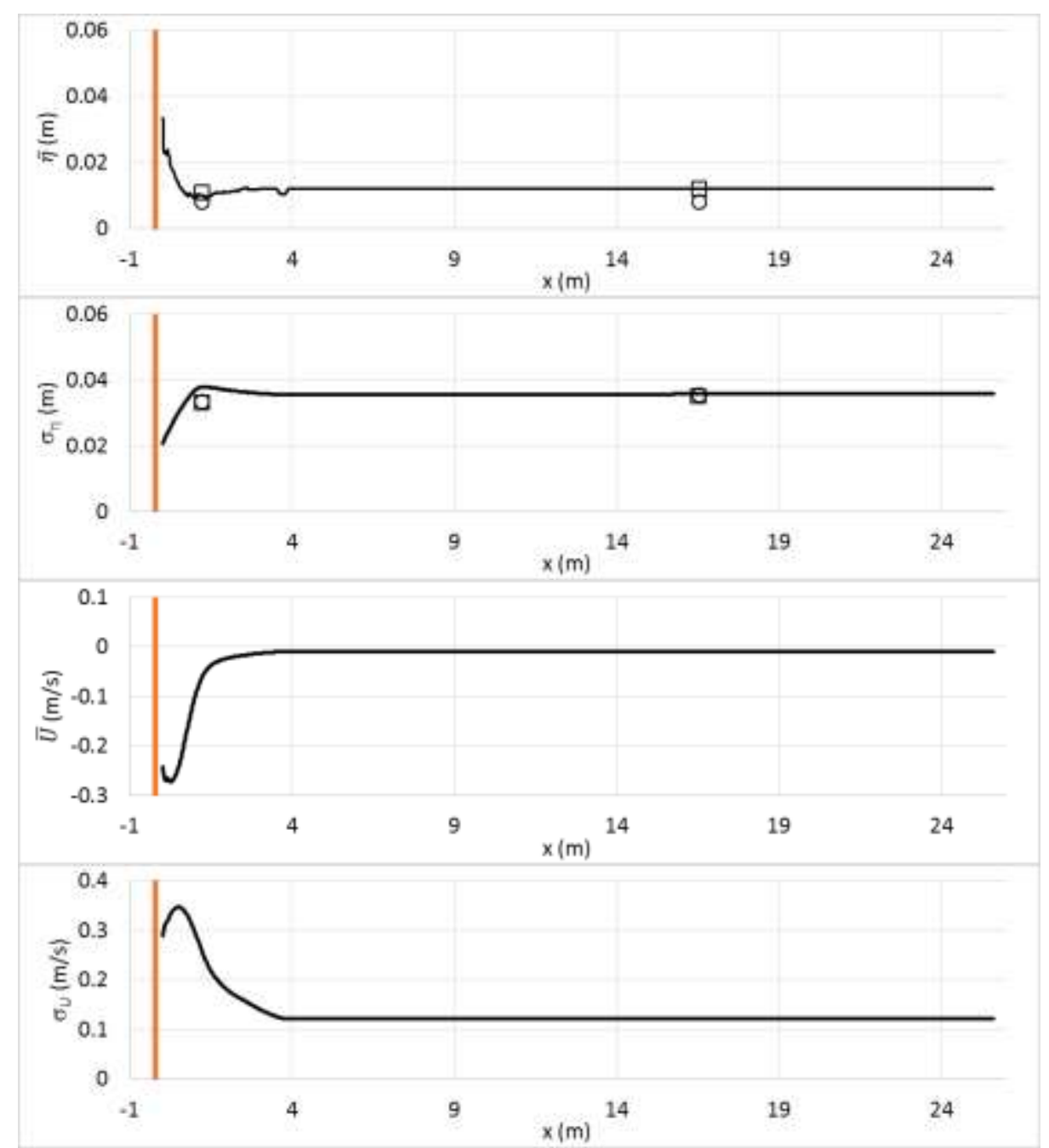

Figure 3. The comparison of measured and numerically predicted values of the hydrodynamic statistics for test W20. Top panel: the mean free surface elevation $\bar{\eta}$, second panel: the standard deviation of the free surface elevation $\sigma_{\eta}$, third panel: the mean cross-shore velocity $\bar{U}$, bottom panel: the standard deviation of the cross-shore velocity $\sigma_{U}$.

Only two wave gauges were used to measure the free surface elevations during the W20 test. In Figure 3, hydrodynamics and the wave transformation could only be compared with these 2 wave gauges. 


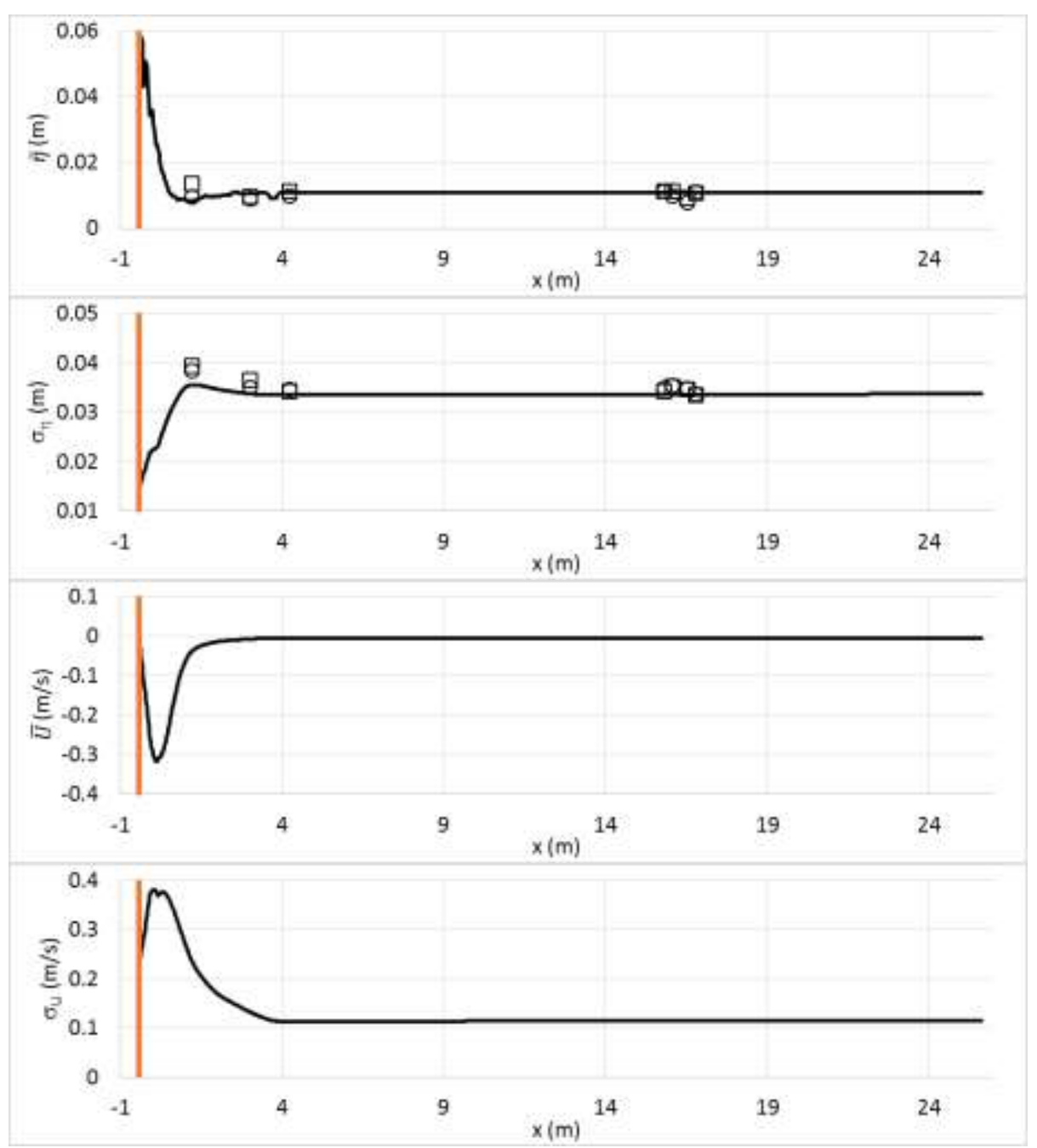

Figure 4. The comparison of measured and numerically predicted values of the hydrodynamic statistics for test W40. Top panel: the mean free surface elevation $\bar{\eta}$, second panel: the standard deviation of the free surface elevation $\sigma_{\eta}$, third panel: the mean cross-shore velocity $\bar{U}$, bottom panel: the standard deviation of the cross-shore velocity $\sigma_{U}$.

The computed cross-shore variations of hydrodynamics and wave transformation variables $\left(\bar{\eta}, \sigma_{\eta}\right.$, $\bar{U}$, and $\sigma_{U}$ ) were presented. Computation was made for $10800 \mathrm{~s}$ (three hours) of time interval. Presented computation results shows the time-averaged values of these parameters during each tests. Because the profile measurements were conducted for the initial and the end profile of each test. But wave measurements were taken for 15 minutes at the beginning of each hour. In Figures 2-4 only one computation line and two markers at each wave gauge location were shown due to the measurement limitations.

In the computations the breaker ratio parameter $\gamma$ was taken as $\gamma=0.8$. This provided well predicted $\sigma_{\eta}$ values along the flume. The $\sigma_{\eta}$ near SWL at WG1 was very well predicted in WW test, overpredicted in W20 test and underpredicted in W40 test. Detailed definition of the time and depth averaged numerical model CSHORE can be found in Kobayashi et. al. (2012). The numerical model consists of the combined wave and current model used in the offshore and surf zone and the probabilistic model for the wet and dry zone. The offshore boundary of the model domain was situated at WG7 just in front of the wave generator. The statistics from WG7 used to define the wave forcing conditions in the numerical model. The cross-shore variation of the mean and standard deviation of the free surface elevation and the undertow current is computed from this offshore boundary to landward by solving the time- averaged linear wave and current equations for continuity, momentum and wave action. In the wet and dry zone, the time-averaged continuity and momentum equations are derived from non-linear 
shallow water wave equations. An exponential probability distribution is assumed for the instantaneous water depth in wet and dry zone.

\section{CROSS-SHORE PROFILE EVOLUTION AND SEDIMENT TRANSPORT}

Sediment transport and the resulting bed profile were also examined by using the cross-shore numerical model CSHORE. The beach profile evolution from the measured initial profile is computed using the continuity equation of the bottom sediment in CSHORE (Kobayashi, 2009).

$$
\left(1-n_{p}\right) \frac{\partial z_{b}}{\partial t}+\frac{\partial q_{x}}{\partial x}=0
$$

where $n_{p}$ is porosity of the bottom sediment, $t$ is the slow morphological time for the change of the bottom elevation, $\mathrm{z}_{\mathrm{b}}$; and $\mathrm{q}_{\mathrm{x}}$ is cross-shore total (bed load plus suspended load) sediment transport rate.

Computed hydrodynamics are used to predict the sediment transport rates and the quasi-equilibrium profile by the sediment transport model in CSHORE. The comparison of the measured and computed profiles for WW test is shown in Figure 5. The trend of the profile change is captured satisfactorily well for this natural beach test. Accretion at the upper end of the beach profile which was observed during the test cannot be captured by the numerical model. The accretion at maximum uprush in the WW test was observed to be a consequence of infiltration at the point of maximum run-up. The sediment transport model used in CSHORE does not account for infiltration directly, instead incorporates it in the hydrodynamic models. This could be a reason for discrepancies in the profile change.

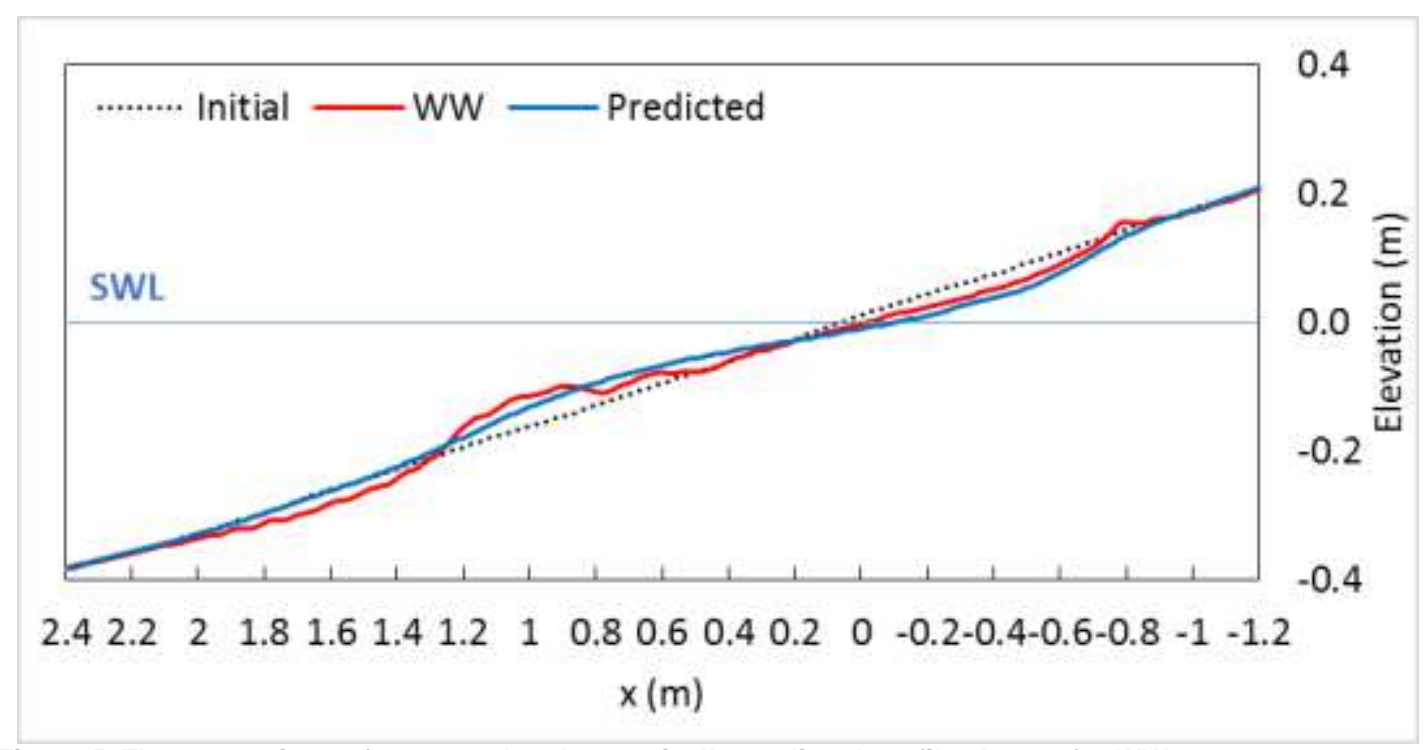

Figure 5. The comparison of measured and numerically predicted profile change for WW test.

The comparisons of the measured and computed profiles for the tests where the seawall was situated inside the run-up region $20 \mathrm{~cm}$ and $40 \mathrm{~cm}$ behind the SWL (W20 and W40) were shown in Figure 6. The trend of the profile change is captured satisfactorily well for each test. Furthermore, the scour depth in front of the vertical wall is predicted satisfactorily by the numerical model. 


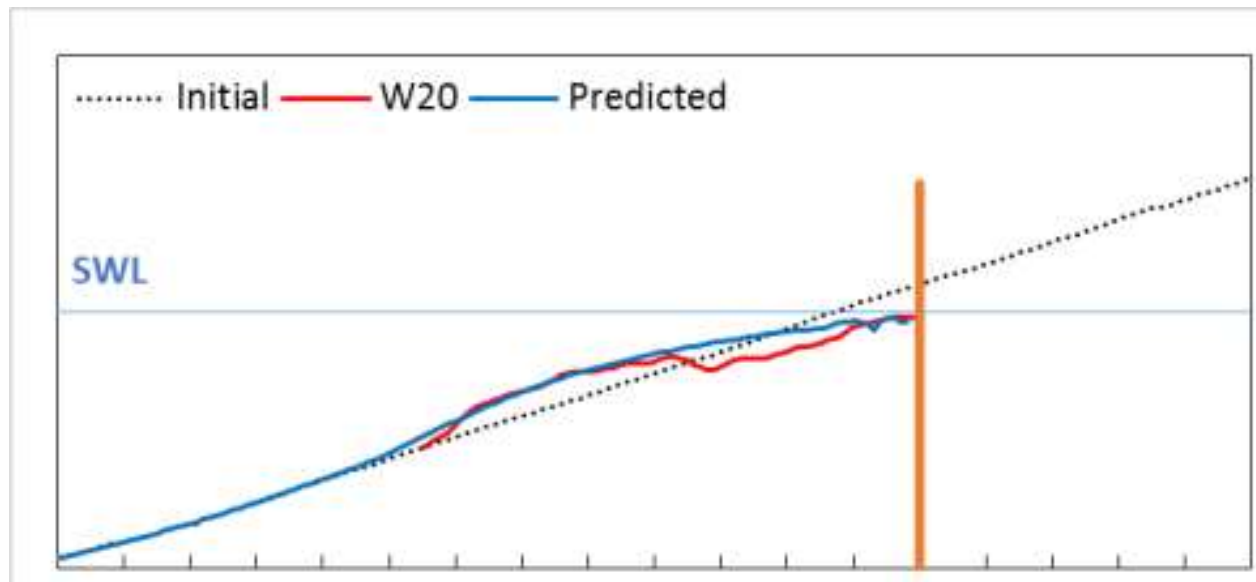

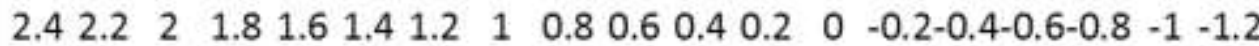
$x(m)$

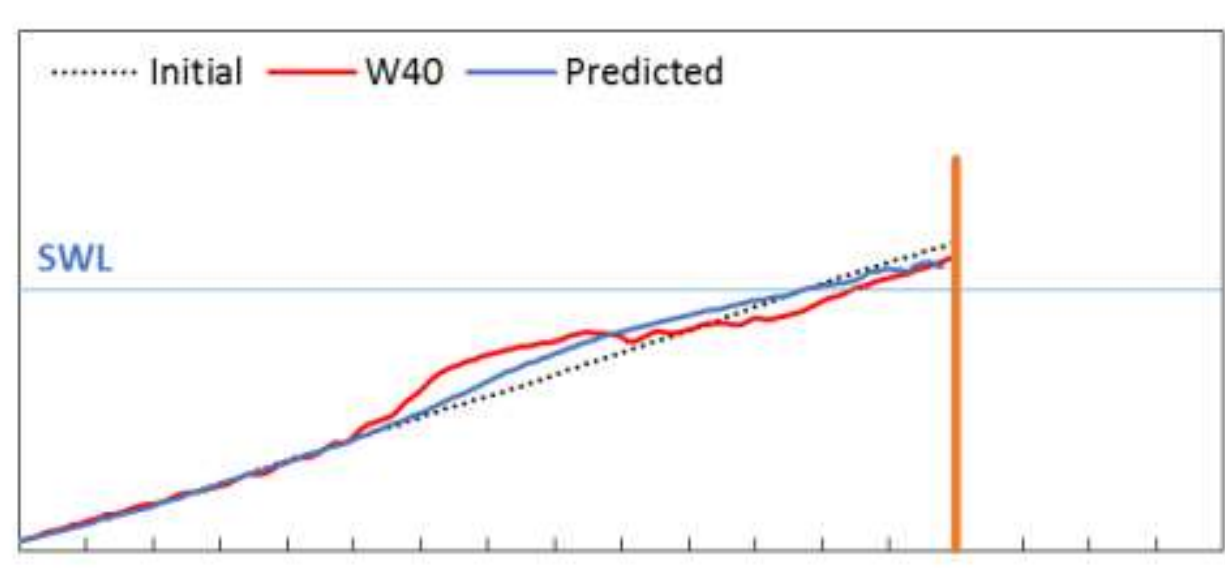

0.4

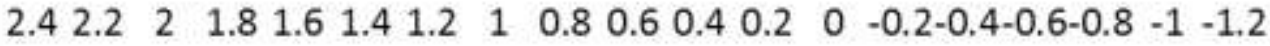 $x(m)$}

Figure 6. The comparison of measured and numerically predicted profile change for tests W20 (top panel), and W40 (lower panel).

The predicted bedload $\mathrm{q}_{\mathrm{b}}$, suspended load $\mathrm{q}_{\mathrm{s}}$, and the net $\mathrm{q}_{\mathrm{x}}\left(=\mathrm{q}_{\mathrm{b}}+\mathrm{q}_{\mathrm{s}}\right)$ sediment transport rates in cross-shore direction for WW and W20 tests are shown in Figure 7. According to the sediment transport model in CSHORE, $\mathrm{q}_{\mathrm{b}}$ and $\mathrm{q}_{\mathrm{s}}$ are related with $\sigma_{U}^{3}$ and $\bar{U}$, respectively. Under normally incident waves, the bedload transport rate $\mathrm{q}_{\mathrm{b}}$ were predicted onshore (positive). The suspended sediment transport rate $\mathrm{q}_{\mathrm{s}}$ is computed to be in offshore (negative) direction because of the undertow current which occurs in offshore direction. As expected, the net sediment transport rates were found to be offshore (negative) and the magnitude of the net transport rate is computed as about $0.007 \mathrm{~cm}^{2} / \mathrm{s}$ for both tests. Figure 7 also reveals that the sediment transport rates are higher in the breaker zone. 


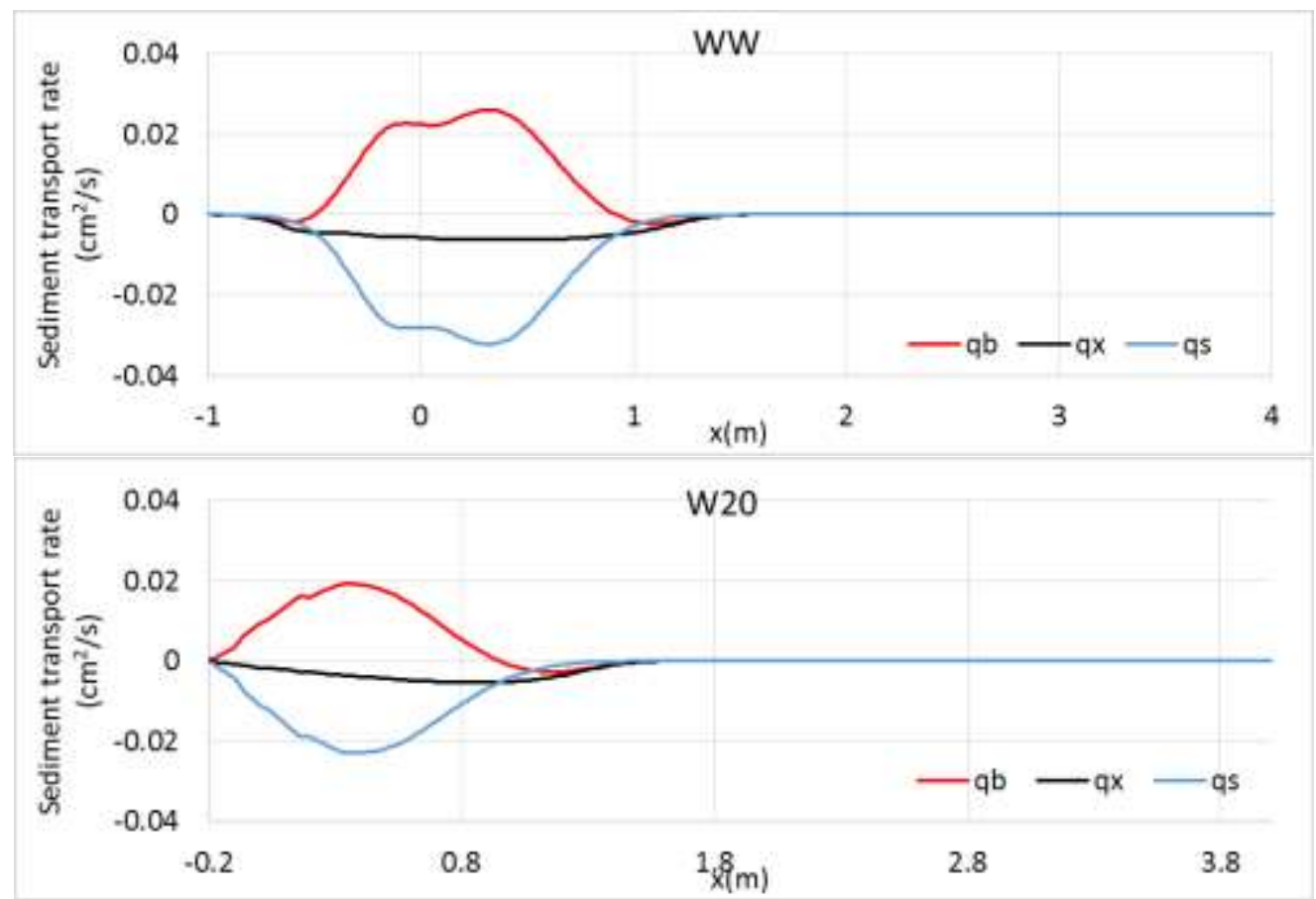

Figure 7. Predicted bedload and suspended sediment transport rates for WW test (top panel) and W20 test (lower panel).

The sensitivity of the computed beach profile evolution to the empirical parameters of $\mathrm{q}_{\mathrm{b}}$ and $\mathrm{q}_{\mathrm{s}}$ was studied as well. The bedload $\mathrm{q}_{\mathrm{b}}$ and suspended $\mathrm{q}_{\mathrm{s}}$ sediment transport rates are related to the bedload parameter $b$ in the range of $b=0.001-0.004$ and the suspended load parameter $a$ in the range of $a=0.1-$ 0.4 , respectively (Kobayashi 2009). The computed results are obtained based on $b=0.004$ and $a=0.2$ in order to increase the onshore bedload transport.

\section{CONCLUSIONS}

Three tests on a sand beach backed by a seawall at two different locations inside the surf zone (Yuksel et. al, 2014) are simulated by using the time-averaged cross-shore numerical model CSHORE to examine profile evolution and sediment transport. Offshore transport was observed in all three tests and the model is shown to predict the same trends in profile evolution. Scour depth in front of the vertical wall is correctly captured by the numerical model. However, some discrepancies in the comparison of the observed profiles with the predicted ones occurred. High reflection coefficients of around 0.2-0.3 were observed in the tests which are characteristic values for steep coarse sand-gravel beaches. This can be a reason for the differences between observed and predicted profiles where CSHORE does not account for wave reflection.

Additional laboratory and field experiments will definitely be needed to assess the accretion and erosion mechanisms on the different sloping beaches in front of the wall situated inside the run-up zone where the wall would be exposed to different waves. Different types of sediments must also be considered in the future laboratory tests.

\section{REFERENCES}

Barnett, M.R., and Wang, H. 1988. Effects of a vertical seawall on profile response, Proceedings of $21^{\text {st }}$ International Conference on Coastal Engineering, ASCE, 1493-1507.

Hicks, B.S., Kobayashi, N., Puleo, J.A., and Farhadzadeh, A. 2010. Cross-shore transport on gravel beaches, Proceedings of $32^{\text {th }}$ International Conference on Coastal Engineering, ASCE.

Johnson, B.D., Kobayashi, N., and Gravens, M.B. 2012. Cross-Shore Numerical Model CSHORE for Waves, Currents, Sediment Transport and Beach Profile Evolution, Coastal and Hydraulics Laboratory, ERDC/CHL TR-12-22.

Kobayashi, N. 2009. Documentation of cross-shore numerical model CSHORE. Research Report No. CACR-09-06, Center for Applied Coastal Research, University of Delaware.

Saitoh, T., and Kobayashi, N. 2012. Wave Transformation and Cross-Shore Sediment Transport on Sloping Beach in Front of Vertical Wall, Journal of Coastal Research, 28(2), 354-359. 
Yüksel, Y., Çevik, E., Aydoğan, B., Kızılöz, B., and Şentürk, E. 2012. Seawall-Beach Profile interaction on run-up zone, Proceedings of ISOPE 2012, Rhodes, Greece.

Yüksel, Y., Yüksel, Z.T., Çevik, E., Ayat, B., Aydoğan, B., Guner, H.A.A., Çelikoğlu, Y., and İşlek, F. 2014. Seawall and beach profile interaction in run-up region, Proceedings of $34^{\text {th }}$ International Conference on Coastal Engineering, ASCE. 